\title{
Use of the rheumatic drug tocilizumab for treatment of SARS-CoV-2 patients
}

\author{
Bogna Grygiel-Górniak ID , Osama Shaikh, Nikita Niranjan Kumar, Shao Heng Hsu ID, \\ Włodzimierz Samborski ID
}

Department of Rheumatology, Rehabilitation and Internal Medicine, Poznan University of Medical Sciences, Poland

\begin{abstract}
Coronavirus disease 2019 (COVID-19) is a highly infectious respiratory disease caused by a new coronavirus known as severe acute respiratory syndrome coronavirus 2 (SARS-CoV-2), which has been observed to vary in its degree of symptoms. One of the most important clinical manifestations is pneumonia and the subsequent worsening of the hyperinflammatory state and cytokine storm. Tocilizumab (TCB) is a recombinant humanized, anti-human monoclonal antibody of the immunoglobulin G1k (lgG1k) subclass that acts against soluble and membrane-bound interleukin six receptors (IL-6R). There is wide use of TCB in rheumatic diseases. However, recently this medication has been used in the treatment of SARS-CoV-2 infection. Tocilizumab application in COVID-19 patients with a high risk of a cytokine storm shows a positive response in reducing the mortality rate. Moreover, TCB minimizes the time needed to recover, improves oxygenation, shortens the duration of vasopressor support, and reduces the likelihood of invasive mechanical ventilation.

Therefore we provide an overview of recent studies to understand the efficacy of this drug under various circumstances, including COVID-19 and rheumatic pathologies. This article also explores and integrates the different treatment possibilities in prominent anti-inflammatory and immunemodulatory-related symptoms. The preliminary data demonstrate promising results regarding the efficacy of TCB use in severe COVID-19 patients. Nevertheless, randomized controlled trials, with adequate sample sizes and sufficient follow-up periods, are needed to form conclusions and establish treatment recommendations.
\end{abstract}

Key words: rheumatic diseases, tocilizumab, coronavirus disease 2019.

\section{Introduction}

Severe acute respiratory syndrome coronavirus 2 (SARS-CoV-2) causes an acute respiratory infectious disease transmitted mainly through the respiratory tract with the host's ability to shed the infection despite being asymptomatic. The virus is an enveloped, large, positive-sense single-stranded RNA of the Coronaviridae family [1], known to infect a broad range of vertebrates [2, 3].

The outbreak of pneumonia cases linked to the new virus SARS-CoV-2 was first reported from Wuhan, China, on December $31^{\text {st }}, 2019[4,5]$. The average incubation period of COVID-19 infection is estimated at up to 5 days, whereas $97.5 \%$ of patients develop symptoms within 11.5 days [6].
The National Institutes of Health $(\mathrm{NIH})$ classify COVID-19 into five categories based on disease severity and clinical presentation. Asymptomatic infection is characterized by a positive test for COVID without clinical symptoms and occurs in approximately $17.9 \%$ to $33.3 \%$ of patients [7].

Many infected subjects present with mild symptoms (70\% in the USA) and typically develop fever and cough without shortness of breath. Less common symptoms of the mild stage include myalgia and headache, at 36\% and $34 \%$, respectively [7].

In moderate COVID-19 illness, individuals have an oxygen saturation greater than or equal to $94 \%$, asso-

Address for correspondence:

Bogna Grygiel-Górniak, Department of Rheumatology, Rehabilitation and Internal Medicine, Poznan University of Medical Sciences, 28 Czerwca St. 135/147, 61-545 Poznan, Poland, e-mail: bgrygiel@ump.edu.pl

Submitted: 18.05.2021; Accepted: 19.07.2021 
ciated with clinical symptoms or radiographic changes in the lower respiratory tract [7]. Such patients are typically hospitalized [6].

Severe SARS-CoV-2 infection is characterized by an oxygen saturation lower than 94\%, tachypnea, and a breathing rate of greater than 30 breaths per minute or pulmonary infiltration higher than $50 \%$ of the lung area.

Lastly, a severe SARS-CoV-2 infection can become critical by developing acute respiratory syndrome (ARDS), defined as acute respiratory failure, multiple organ dysfunction and/or sepsis, which develop within a week from the first symptoms [7].

SARS-CoV-2, via its surface spike glycoprotein, interacts with angiotensin-converting enzyme 2 (ACE2) receptors, invades the respiratory host cell, and induces an immune response [8]. Typically, viruses invade the host's body and bind to pathogen-associated molecular patterns (PAMPs) and pattern recognition receptors (PRRs).

This binding triggers an inflammatory response against the invading virus, which leads to the activation of several signaling pathways and transcription factors that subsequently induce the expression of genes. These genes encode for chemokines, inflammatory cytokines, and adhesion molecules.

Consequently, there is an increased level of leukocytes, and there is initiation of the recruitment of plasma proteins to the infection site, subsequently destroying the lung tissue [9]. The most critical pro-inflammatory cytokines produced by the innate immune response cells are IL-1, TNF- $\alpha$, and IL- 6 [10].

A sudden increase of these cytokines, known as the cytokine release storm (CRS), is observed in some patients with severe COVID-19 symptoms [5, 11]. Excessive local release of such protein molecules results in a broad spectrum of destruction, including diffuse alveolar damage, multiorgan failure, and ultimately death, similar to $\operatorname{ARDS}[5,9]$.

Interleukin 6 has a broad spectrum of biological activities, including regulating specific differentiation of naïve CD4+ T-cells and activation of vascular endothelial cells, which are pathologically involved in developing various autoimmune and chronic inflammatory diseases [12].

The consideration for TCB's possible use in SARS-CoV-2 infection started when clinicians noticed significantly increased serum IL- 6 in severely ill patients with extensive bilateral lung lesions. Thus, tocilizumab (a humanized IgG1 monoclonal antibody to the IL-6 receptor) can be a promising therapy for COVID-19 [13].

Previously this medication was categorized into a disease-modifying antirheumatic drug (DMARD) and is used in the treatment of rheumatoid arthritis (RA), juvenile idiopathic arthritis (JIA), and other chronic con- nective tissue diseases [8, 14, 15]. Since there is growing interest in TCB's effects in the treatment of COVID-19, this review highlights the various studies from 2019 to 2021 and appraises TCB's efficacy to treat both COVID-19 and rheumatic diseases.

\section{Cytokine storm}

A cytokine storm is an uncontrolled systemic inflammatory response that results in an elevated level of circulating chemokines and cytokines by immune system hyperactivation. Common etiologies include hemophagocytic lymphohistiocytosis (HLH), JIA, sepsis, and CAR T therapy $[16,17]$.

Diagnosing the cause of cytokine storms is challenging since the laboratory parameters vary and are mainly influenced by the underlying cause. The severity of cytokine release can correlate with an elevated level of C-reactive protein (CRP), which is a nonspecific marker of inflammation. Other abnormalities include leukocytosis, leukopenia, anemia, thrombocytopenia, and high ferritin and D-dimer levels [16].

The phenomenon of the cytokine storm also occurs in other diseases such as HLH and macrophage activation syndrome (MAS). Both these diseases rely on their respective established criteria. Recent research suggests that the COVID-19 associated cytokine storm is unique, and the classification criteria of MAS (2016) or HLH (2004) are not applicable for predicting cytokine synthesis in SARS-CoV-2 patients [18-20].

The diagnosis of $\mathrm{HLH}$ is based on five from eight major criteria: fever, splenomegaly, cytopenia, hypertriglyceridemia, and/or hypofibrinogenemia, hemophagocytosis, low/absent NK cell activity, hyperferritinemia, and high-soluble interleukin-2-receptor levels [19].

The research of Caricchio et al. [18] showed that COVID-19 patients usually have normal monocyte levels, increased neutrophil concentration, and they do not develop splenomegaly or cytopenia. Moreover, they also have normal or elevated fibrinogen levels (typically low in $\mathrm{HLH}$ ) and normal triglycerides (which are frequently increased in $\mathrm{HLH}$ ). Thus, COVID-19 patients do not qualify for the HLH criteria [18].

Macrophage activation syndrome (MAS) is triggered by rheumatic diseases such as systemic lupus erythematosus (SLE) or JIA. Clinical symptoms involve multiorgan dysfunction and shock in febrile hospitalized patients [19].

Macrophage activation syndrome criteria in systemic juvenile idiopathic arthritis include ferritin $>684 \mathrm{ng} / \mathrm{ml}$ and any two of the following: platelet count $<181 \times 10^{9} / \mathrm{l}$, aspartate aminotransferase > $48 \mathrm{IU} / \mathrm{l}$, triglycerides $>156 \mathrm{mg} / \mathrm{dl}$ and fibrinogen < $360 \mathrm{mg} / \mathrm{dl}$ [20]. 
Caricchio et al. [18] observed that COVID-19 patients do not meet the MAS criteria, because SARS-CoV-2 individuals usually do not develop thrombocytopenia or hyperfibrinogenemia, and they have relatively normal levels of triglycerides.

\section{Tocilizumab - mechanism of action}

Tocilizumab use in rheumatic diseases is based on the fact that the synoviocytes release IL-6. Decades of research have investigated IL- 6 and its role in the pathogenesis of rheumatoid arthritis, which entails a complicated process of cellular reactions, infiltration of lymphocytes, immune complexes, and vascular reactions in the synovium.

However, the role of IL-6 in autoimmune diseases is pleiotropic. IL-6 stimulates B-cell maturation and subsequent stimulation of autoantibodies. Consequently, an increased level of C-reactive protein (CRP) released from hepatocytes is observed [21, 22].

Understanding IL- 6 's role in the course of complications of the acute phase of COVID-19 suggested a possible role of TCB in the state of viral overload. Tocilizumab's mechanism in treating severe COVID-19 remains uncertain; however, its activity is best understood based on the ample existing knowledge of IL-6 in the field of rheumatology.

Interleukin 6 can bind to two receptors; either a membrane-bound receptor (miL-6R) or a soluble form (siL-6R) which is not bound to the cell's membrane. When IL- 6 binds to miL-6R, it forms a complex which connects the signal transducer glycoprotein 130 (gp130)

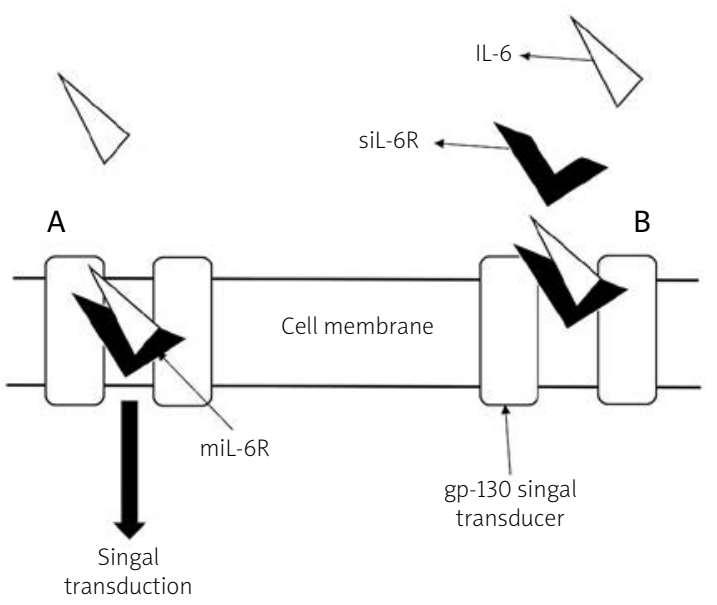

Fig. 1. The mechanism whereby IL-6 cytokine binds to miL-6R (A) and also the soluble receptor (B). Following the IL-6 and IL-6R complex, the multipart adheres to the gp130 transducer molecule, which initiates downstream signaling. to produce a set of downstream responses, such as antiinflammatory reactions (shown in Fig. 1A).

These reactions are limited to the cells expressing miL-6R, such as T-cells, neutrophils, and macrophages. However, the trans-signaling pathway entails binding the cytokine IL-6 to siL-6R with the subsequent complex binding to a gp130 transducer resulting in a pro-inflammatory response in almost every cell of the body (shown in Fig. 1B) [23].

The trans-signaling pathway can occur in situations where IL-6 is elevated (e.g., rheumatoid arthritis, CRS in COVID-19) and in the absence of miL-6R since the siL-6/IL-6 complex binds to the gp-130 transducer, which is expressed in every cell of the body [24].

Tocilizumab can adhere to IL-6 and both forms, miL-6R and siL-6R, therefore inhibiting signal transduction mediated by IL- 6 and the downstream inflammatory effects (shown in Fig. 2) [25].

Based on the knowledge of the cellular pathway whereby TCB functions in the treatment of RA, this mechanism of action of TCB can explain the beneficial effect of TCB in the treatment of CRS present in the course of COVID-19 [24, 26]. The hyperinflammatory response is an underlying cause of the CRS, which is currently clinically apparent in COVID-19 patients [27].

With the FDA approving TCB's use in cytokine release syndromes [24], a study in China tested its effectiveness in treating severe SARS-CoV-2 infection and obtained promising results. Following this trial, the COVID-19 ( $7^{\text {th }}$ edition) diagnosis and treatment program of China's national health commission formally included TCB in the COVID-19 regimen [28].

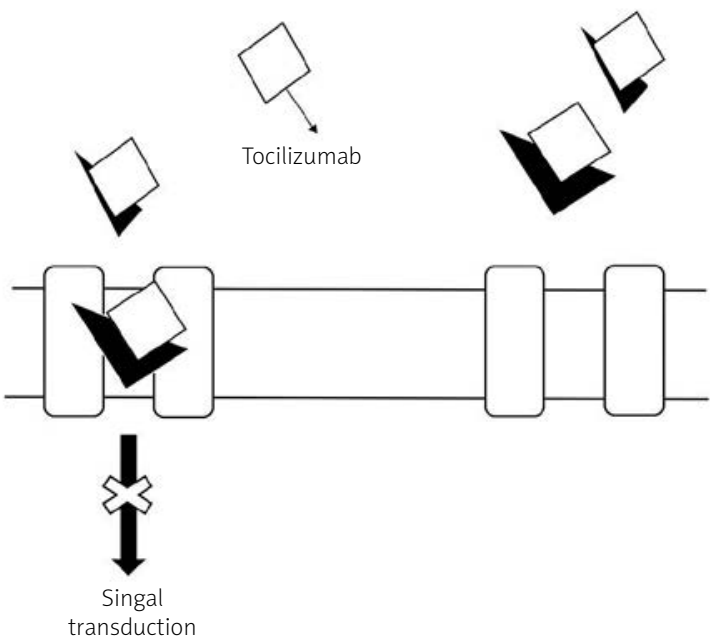

Fig. 2. The action of tocilizumab. The IL- 6 antagonist binds to IL- 6 directly as well as both miL-6R and siL-6R. This blockage prevents gp130 from being activated, and hence the subsequent downstream signaling cascade is halted. 


\section{Use of tocilizumab in rheumatology associated with cytokine storms}

Tocilizumab has been studied in pathologies such as SLE, JIA, and refractory adult-onset Still's disease (AOSD). Tocilizumab is efficient at treating JIA cases that have previously been refractory to DMARDs [29]. In adult-onset Still's disease, some patients may substantially respond to TCB by achieving remission [30].

As a direct antagonist against IL-6R, TCB has been a cornerstone in treating CAR (chimeric antigen receptors) T-cell therapy-induced cytokine storm present also in other rheumatic diseases. Recently, greater insight into CAR T-cell therapy-induced cytokine storm mechanisms has been obtained via combining correlative sciences and retrospective analysis of clinical trials [31].

However, the precise mechanisms are poorly understood and complicated. When CAR T-cells come into contact with target cells (myeloid and endothelial), they release inflammatory cytokines such as TNF- $\alpha$ and IFN- $\gamma$, which in turn activate monocytes and macrophages to secrete IL-1 and IL-6 [32].

In such an inflammatory state, TCB could be a suitable choice as it binds to membrane-bound as well as soluble IL-6R, hence interfering with both classical and trans-signaling pathways [33]. Subsequent ongoing studies have shown that administration of TCB led to rapid resolution of cytokine storm symptoms of postCAR T-cell therapy $[33,34]$.

The United States Food and Drug Administration approved TCB in 2018 to treat severe or life-threatening CAR T-cell-induced CRS in adults and pediatric patients aged two years and older [35].

Thus, the role of IL-6 in COVID-19 pathophysiology alongside the mechanism of TCB's action in the CAR T-induced cytokine storm forms the background to consider this drug as a treatment option for COVID-19 [36, 37].

\section{Use of tocilizumab in COVID-19}

Many studies have tested the effectiveness of TCB in SARS-CoV-2 infection (Table I). An observational study which compared COVID-19 patients receiving TCB with a control group without TCB showed that fewer individuals required mechanical ventilation if they were treated with TCB, particularly in those patients who had more significant lung damage shown in a computed tomography scan.

Thus, this study's authors stated that clinical indications for use of this drug include extensive regions involving both lungs and considerable impairment in respiration to the extent that oxygen supplementation of at least $5 \mathrm{l} / \mathrm{min}$ is required [38].
A similar study by Yuan et al. [39] revealed that TCB potentially dampens the hyperinflammatory state and the associated cytokine storm, mainly in patients with extensive lung involvement on CT scans.

Elevated CRP level, IL-6, and ferritin are the proinflammatory laboratory markers that are further associated with pulmonary damage, and hence poor prognostic factors are indications for TCB initiation [37].

In addition, a large lung area affected during SARS-CoV-2 infection indicates disease severity and mortality from the COVID-19 condition. Thus, TCB seems desirable in treating COVID-19, especially in severe lung damage cases [39]. Tocilizumab's effective use was also reported in patients with Sjögren's syndrome, who suffered from COVID19-induced severe respiratory distress but which was immediately alleviated by a single dose of off-label TCB [40].

Another beneficial effect of TCB in COVID-19 patients was demonstrated in a retrospective cohort study, comparing the outcome between patients receiving TCB versus those who did not (control group). Tocilizumab's use resulted in desirable effects, such as shorter time to clinical improvement, shorter duration of vasopressor support, and reduced time required for mechanical ventilation compared to the control group.

The results imply that the use of TCB for severe cases of COVID-19 may reduce the time needed to recover, hence lowering the load imposed on healthcare resources and facilities [41].

The strong evidence of TCB effectiveness was confirmed in a systematic review and meta-analysis conducted by Ruscitti et al. [42], who analyzed 22 studies, including patients from China, Italy, the US, France, Turkey, Qatar, and those who received TCB. The pooled prevalence for mortality in COVID-19 patients treated with TCB was lower than in the overall group of patients who received other treatment forms [42].

A similar conclusion was presented in the review by Kaye et al. [43], who confirmed that TCB has efficacy in limiting the fatal outcome of SARS-CoV-2 infection.

Moreover, a meta-analysis including patients from the USA, Italy, France, and Spain showed that TCB's addition to the existing standard care for COVID-19 might increase the disease's positive outcome [44]. Adding TCB to the typical treatment of COVID-19 reduced the need for mechanical ventilation and resulted in no increased risk of infection or adverse events [45].

Likewise, an observational study by Biran et al. [46] in 2020 found that TCB treatment in COVID-19 patients in the ICU reduced the mortality rate. Carvalho et al. [47] in 2020 found that TCB improved oxygenation and decreased inflammatory markers, suggesting that this medication can be a rescue therapy for those with a severe form of the disease. 
Table I. Effectiveness of tocilizumab in hospitalized COVID-19 patients

\begin{tabular}{|c|c|c|c|c|}
\hline Study & Dose of TCB & $n$ & Treatment duration & Effect of TCB on COVID-19 \\
\hline $\begin{array}{l}\text { Kewan et al. } \\
\text { [41] } 2020\end{array}$ & $8 \mathrm{mg} / \mathrm{kg}$ up to $400 \mathrm{mg}$ & 28 & 60-minute single i.v. infusion & $\begin{array}{c}\quad \downarrow \text { time to clinical recovery } \\
\downarrow \text { time of mechanical ventilation } \\
\text { necessity } \\
\downarrow \text { duration of vasopressor support }\end{array}$ \\
\hline $\begin{array}{l}\text { Guaraldi et al. } \\
\text { [48] } 2020\end{array}$ & $\begin{array}{c}8 \mathrm{mg} / \mathrm{kg} \\
\text { - maximum at } 800 \mathrm{mg} \\
162 \mathrm{mg} \text { s.c. }\end{array}$ & 179 & $\begin{array}{l}2 \text { i.v. doses ( } 12 \text { hours apart) } \\
\text { at } 2 \text { simultaneous s.c. doses }\end{array}$ & $\begin{array}{c}\downarrow \text { mortality rate } \\
\downarrow \text { risk of invasive mechanical } \\
\text { ventilation and death }\end{array}$ \\
\hline $\begin{array}{l}\text { Carvalho et al. } \\
{[47] 2020}\end{array}$ & $400 \mathrm{mg}$ & 29 & 2 i.v. doses & $\begin{array}{c}\text { improvement in oxygenation } \\
\text { quicker } \downarrow \text { in CRP levels and WBC } \\
\text { counts }\end{array}$ \\
\hline $\begin{array}{l}\text { Biran et al. } \\
{[46] 2020}\end{array}$ & $400 \mathrm{mg}$ & 210 & $\begin{array}{c}1 \text { i.v. dose } \\
2^{\text {nd }} i . v . \text { dose permitted before } \\
\text { the clinical worsening }\end{array}$ & $\begin{array}{l}\uparrow \text { mortality in those who did not } \\
\text { receive TCB }\end{array}$ \\
\hline $\begin{array}{l}\text { Albertini et al. } \\
\text { [38] } 2020\end{array}$ & $\begin{array}{l}600 \mathrm{mg} \text { if weight } \\
<100 \mathrm{~kg} \text { or } 800 \mathrm{mg} \\
\text { if weight }>100 \mathrm{~kg}\end{array}$ & 22 & $\begin{array}{l}\text { One-time dose } i . v . \\
2^{\text {nd }} \text { dose administered if no } \\
\text { response at } 48 \text { hours after } \\
\text { the first dose }\end{array}$ & $\begin{array}{c}\downarrow \text { respiratory rate } \\
\downarrow \text { need for mechanical ventilation } \\
\text { (particularly in patients with } \\
\text { damage in lungs greater than } 50 \% \\
\text { indicated on CT scan) }\end{array}$ \\
\hline $\begin{array}{l}\text { Menzella et al. } \\
\text { [53] } 2020\end{array}$ & $\begin{array}{l}8 \mathrm{mg} / \mathrm{kg} \text { up to } 800 \mathrm{mg} \text { i.v. } \\
162 \mathrm{mg} \text { s.c. }\end{array}$ & 41 & $\begin{array}{c}2 \text { i.v. doses, each } 12 \text { hours } \\
\text { apart } 2 \text { to } 4 \text { simultaneous s.c. } \\
\text { doses }\end{array}$ & $\begin{array}{c}\text { Quicker } \downarrow \text { CRP } \\
\downarrow \text { mortality rate in-hospital } \\
(24 \% \text { with TCB vs. } 53 \% \text { with } \\
\text { the standard care })\end{array}$ \\
\hline $\begin{array}{l}\text { Stone et al. } \\
\text { [50] } 2020\end{array}$ & $8 \mathrm{mg} / \mathrm{kg}$ of body weight & 161 & Single-dose i.v. & $\begin{array}{c}\text { No beneficial effect of TCB } \\
\text { in preventing intubation or death } \\
\text { in patients who were hospitalized } \\
\text { due to moderate COVID-19 } \\
\text { infection }\end{array}$ \\
\hline $\begin{array}{l}\text { Salama et al. } \\
\text { [52] } 2020\end{array}$ & $8 \mathrm{mg} / \mathrm{kg}$ of body weight & 249 & 1 or 2 i.v. doses & $\begin{array}{c}\downarrow \text { risk of progression to the } \\
\text { composite outcome of mechanical } \\
\text { ventilation or death (but TCB } \\
\text { did not increase the chances of } \\
\text { survival) }\end{array}$ \\
\hline $\begin{array}{l}\text { Horby et al. } \\
\text { [51] } 2021\end{array}$ & $\begin{array}{c}800 \mathrm{mg} \text { if weight }>90 \mathrm{~kg} \\
600 \mathrm{mg} \text { if weight }>65 \mathrm{~kg} \leq 90 \\
400 \mathrm{mg} \text { if weight }>40 \mathrm{~kg} \leq 65 \mathrm{~kg} \\
8 \mathrm{mg} / \mathrm{kg} \text { if weight } \leq 40 \mathrm{~kg}\end{array}$ & 2022 & $\begin{array}{l}\text { One-time i.v. infusion over } \\
60 \text { minutes } \\
2^{\text {nd }} \text { dose administered } \\
\text { 12-24 hours later if condition } \\
\text { not improved }\end{array}$ & $\begin{array}{l}\downarrow \text { death rate within } 28 \text { days } \\
\uparrow \text { patients discharged from } \\
\text { hospital within } 28 \text { days }\end{array}$ \\
\hline $\begin{array}{l}\text { Rosas et al. } \\
\text { [49] } 2021\end{array}$ & $8 \mathrm{mg} / \mathrm{kg}$ of body weight & 294 & $\begin{array}{c}\text { i.v. transfusion } \\
2^{\text {nd }} \text { dose given } 8-24 \text { hours } \\
\text { following } 1^{\text {st }} \text { dose in a quarter } \\
\text { of patients }\end{array}$ & $\begin{array}{l}\text { Serious adverse events in } 34.9 \% \text { of } \\
\text { patients treated with TCB compared } \\
\text { to } 38.5 \% \text { in placebo group } \\
19.7 \% \text { mortality at day } 28 \text { for TCB } \\
\text { (compared to } 19.4 \% \text { in placebo) }\end{array}$ \\
\hline
\end{tabular}

TCB - tocilizumab, $n$ - number of patients, i.v. - intravenous, s.c. - subcutaneous.

A retrospective, observational cohort study by Guaraldi et al. [48] in 2020 demonstrated that either intravenous or subcutaneous TCB administration might reduce the likelihood of invasive mechanical ventilation or death in patients suffering from severe COVID-19.

In contrast, a randomized trial by Rosas et al. [49] in 2021 showed that TCB treatment in patients with severe COVID-19 did not significantly improve clinical status or lower the mortality rate at day 28.
In a randomized, double-blind, placebo-controlled trial, no effect in preventing intubation or death in patients with severe acute COVID-19 infection was observed [50]. Data presented from the Randomized Controlled Open-label Platform (RECOVERY) trial concluded that regardless of the level of respiratory support required, administering TCB improved survival and clinical outcome in patients admitted to the hospital due to hypoxia and systemic inflammation [51]. 


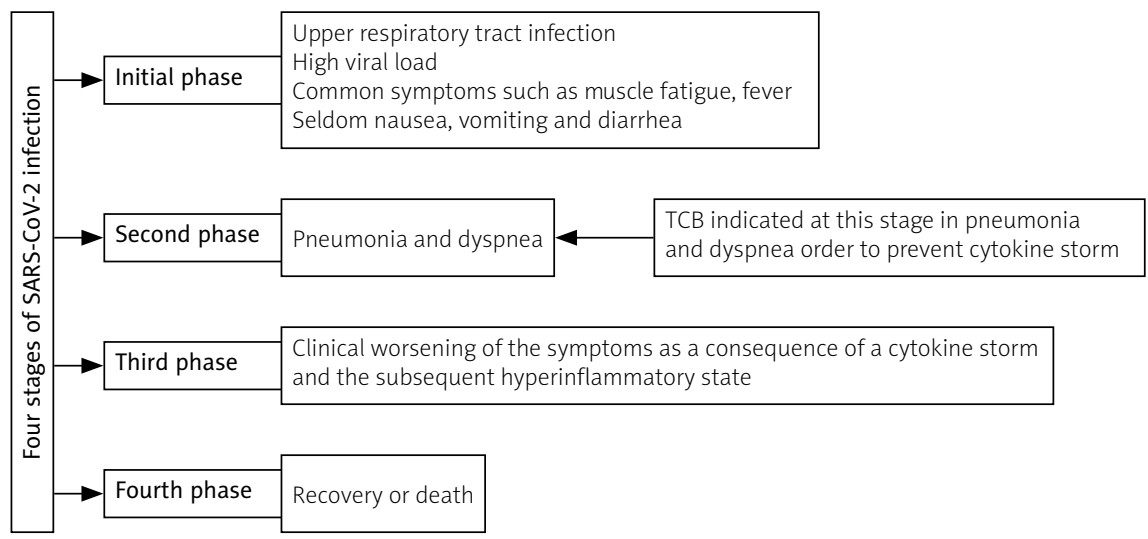

Fig. 3. Four stages of COVID-19 and the initiation of tocilizumab therapy.

The efficacy of TCB was also studied in patients with mild COVID-19 infection not requiring mechanical ventilation. The authors of this study noted that decreased probability of needing ventilatory support in the future was observed in patients who were treated with TCB. However, management with TCB did not improve the analyzed patients' overall survival [52].

\section{Tocilizumab treatment guidelines of SARS-CoV-2 infected patients}

The insufficient scientific evidence to support the ongoing treatment for COVID-19 has resulted in continuous alterations of treatment guidelines and procedures [5]. Currently, highly effective treatment for COVID-19 infection is absent, and clinical researchers are basing the treatments and therapies provided on the clinical stage and pathological features of COVID-19 [54]. There are four stages of COVID-19, which have been modelled based on published studies (Fig. 3) [55].

During the early phase of the disease, characterized by a high viral load (SARS-CoV-2 replication at its peak), the use of remdesivir and SARS-CoV-2 monoclonal antibodies (convalescent plasma, REGN-COV2) is recommended. In the later (hyperinflammatory) stage, dexamethasone and TCB should be used (FDA statement) [24, 35].

The National Institutes of Health $(\mathrm{NIH})$ guidelines state that tocilizumab should be administered as a single IV dose in hospitalized patients due to a severe or critical COVID-19 state with impending respiratory deterioration. These recommendations are based on trials that have shown decreased mortality in individuals who had a rapid decline in respiratory function and received TCB therapy [7].

A meta-analysis by Hariyanto and Kurniawan [56] concluded that TCB treatment in COVID-19 lowers CRP, ferritin, and D-dimer levels while increasing the white cell count. The pharmacokinetic and pharmacody- namic study of TCB revealed that a dose of $600 \mathrm{mg}$ is optimal in ICU admitted patients. Such a dose causes less variability exposure in comparison to the calculated body weight doses. It prevents the potential underexposure in low body mass patients and unnecessary overexposure in those with high body mass [57].

Additionally, a wide range of treatments, such as immunotherapy, cellular therapy, and supportive management, are used for the regimen in COVID-19 [58]. Supportive treatment involves taking rest, monitoring vital signs such as pulse, oxygen saturation, and respiratory rate.

Additionally, adequate rest with sufficient food and water intake alongside antipyretic medications for fever and moderate pain is also recommended [59]. Cellular therapy entails the use of mesenchymal stem cells (MSCs), which can be isolated from peripheral blood, placenta, and umbilical cord blood. Mesenchymal stem cells are recognized for their prominent anti-inflammatory and immune-modulatory properties, which can help suppress the CRS in COVID-19 and potentially limit the disease from progressing to a critical phase and ultimately death.

Another treatment option is immunotherapy, based on collected convalescent plasma from patients who have recovered from COVID-19 [59]. Towards the end of 2020, a vaccine for COVID-19 became available for public use [60].

\section{Conclusions}

Since the fast spread of SARS-CoV-2 infection, the scientific and medical world has concentrated on finding effective therapy. Tocilizumab, a drug used in the treatment of rheumatic diseases, raises clinical interest as a potential medication used in COVID-19. This medication is used with good effect in treating rheumatic diseases such as RA, JIA, SLE, giant cell arteritis, and Kawasaki disease.

A vast range of promising data have shown this drug's effectiveness in treating severe COVID-19 cases 
and reducing the mortality rate. However, the results must be treated with caution since most of these studies used a small sample size, had a short follow-up period, and were not randomized controlled trials.

Nevertheless, TCB has been proven to reduce disease severity in severely ill patients by improving various clinical outcomes and ultimately lowering healthcare workers' and centers' burden.

The authors declare no conflict of interest.

\section{References}

1. Huang C, Wang Y, Li X, et al. Clinical features of patients infected with 2019 novel coronavirus in Wuhan, China. Lancet 2020; 395: 497-506, DOI: 10.1016/S0140-6736(20)30183-5.

2. BalochS, Baloch MA,Zheng T,PeiX. The coronavirus disease 2019 (COVID-19) pandemic. Tohoku J Exp Med 2020; 250: 271-278, DOI: $10.1620 /$ tjem.250.271.

3. Asselah T, Durantel D, Pasmant E, et al. COVID-19: Discovery, diagnostics and drug development. J Hepatol 2021; 74: 168184, DOI: 10.1016/j.jhep.2020.09.031.

4. Lotfi M, Hamblin MR, Rezaei N. COVID-19: transmission, prevention, and potential therapeutic opportunities. Clin Chim Acta 2020; 508: 254-266, DOI: 10.1016/j.cca.2020.05.044.

5. Ragab D, Salah Eldin H, Taeimah M, et al. The COVID-19 cytokine storm; what we know so far. Front Immunol 2020 16; 11: 1446, DOI: 10.3389/fimmu.2020.01446.

6. Wiersinga WJ, Rhodes A, Cheng AC, et al. Pathophysiology, transmission, diagnosis, and treatment of coronavirus disease 2019 (COVID-19). JAMA 2020; 324: 782, DOI: 10.1001/ jama.2020.12839.

7. Cascella M, Rajnik M, Aleem A, et al. Features, evaluation, and treatment of coronavirus (COVID-19) [Updated 2021]. In: StatPearls [Internet]. Treasure Island (FL): StatPearls Publishing; 2021 [Available from: https://www.ncbi.nlm.nih.gov/books/ NBK554776/].

8. Amraei R, Rahimi N. COVID-19, renin-angiotensin system and endothelial dysfunction. Cells 2020; 9: 1652, DOI: 10.3390/ cells9071652.

9. Hu B, Huang S, Yin L. The cytokine storm and COVID-19. J Med Virol 2021; 93: 250-256, DOI: 10.1002/jmv.26232.

10. Scott LJ. Tocilizumab: a review in rheumatoid arthritis. Drugs 2017; 77: 1865-1879, DOI: 10.1007/s40265-017-0829-7.

11. Samaee H, Mohsenzadegan M, Ala S, et al. Tocilizumab for treatment patients with COVID-19: recommended medication for novel disease. Int Immunopharmacol 2020; 89: 107018, DOI: 10.1016/j.intimp.2020.107018.

12. Tanaka T, Narazaki M, Kishimoto T. Interleukin (IL-6) immunotherapy. Cold Spring Harb Perspect Biol 2018; 10: a028456, DOI: 10.1101/cshperspect.a028456.

13. Luo P, Liu Y, Qiu L, et al. Tocilizumab treatment in COVID-19: a single center experience. J Med Virol 2020; 92: 814-818, DOI: 10.1002/jmv.25801.

14. Li Q, Guan X, Wu P, et al. Early transmission dynamics in Wuhan, China, of novel coronavirus-infected pneumonia. N Engl J Med 2020; 382: 1199-1207, DOI: 10.1056/NEJMoa2001316.
15. Sheppard M, Laskou F, Stapleton PP, et al. Tocilizumab (Actemra). Hum Vaccin Immunother 2017; 13: 1972-1988, DOI: 10.1080/21645515.2017.1316909.

16. Fajgenbaum DC, June CH. Cytokine Storm. Longo DL, editor. N Engl J Med 2020; 383: 2255-2273, DOI: 10.1056/NEJMra2026131.

17. Nile SH, Nile A, Qiu J, et al. COVID-19: pathogenesis, cytokine storm and therapeutic potential of interferons. Cytokine Growth Factor Rev 2020; 53: 66-70, DOI: 10.1016/j.cytogfr. 2020.05.002.

18. Caricchio R, Gallucci M, Dass C, et al. Preliminary predictive criteria for COVID-19 cytokine storm. Ann Rheum Dis 2020; 80: 88-95, DOI: 10.1136/annrheumdis-2020-218323.

19. Cron RQ, Davi S, Minoia F, Ravelli A. Clinical features and correct diagnosis of macrophage activation syndrome. Expert Rev Clin Immunol 2015; 11: 1043-1053, DOI: 10.1586/1744666X.2015.1058159.

20. Ravelli A, Minoia F, Davì S, et al. 2016 Classification Criteria for Macrophage Activation Syndrome Complicating Systemic Juvenile Idiopathic Arthritis: A European League Against Rheumatism/American College of Rheumatology/Paediatric Rheumatology International Trials Organisation Collaborat. Arthritis Rheumatol 2016; 68: 566-676, DOI: 10.1002/art.39332.

21. Srirangan S, Choy EH. The role of interleukin 6 in the pathophysiology of rheumatoid arthritis. Ther Adv Musculoskelet Dis 2010; 2: 247-256, DOI: 10.1177/1759720X10378372.

22. Kim GW, Lee NR, Pi RH, et al. IL-6 inhibitors for treatment of rheumatoid arthritis: past, present, and future. Arch Pharm Res 2015; 38: 575-584, DOI: 10.1007/s12272-015-0569-8.

23. Okuda Y. Review of tocilizumab in the treatment of rheumatoid arthritis. Biologics 2008; 2: 75-82, DOI: 10.2147/btt.s1828.

24. Zhang S, Li L, Shen A, et al. Rational use of tocilizumab in the treatment of novel coronavirus pneumonia. Clin Drug Investing 2020; 40: 511-518, DOI: 10.1007/s40261-020-00917-3.

25. Tanaka T, Narazaki M, Kishimoto T. IL-6 in inflammation, immunity, and disease. Cold Spring Harb Perspect Biol 2014; 6 : a016295, DOI: 10.1101/cshperspect.a016295.

26. Patel A, Shah K, Dharsandiya M, et al. Safety and efficacy of tocilizumab in the treatment of severe acute respiratory syndrome coronavirus-2 pneumonia: a retrospective cohort study. Indian J Med Microbiol 2020; 38: 116-122, DOI: 10.4103/ ijmm.IJMM_20_298.

27. Cortegiani A, Ippolito M, Greco M, et al. Rationale and evidence on the use of tocilizumab in COVID-19: a systematic review. Pulmonology 2021; 27: 52-66, DOI: 10.1016/j.pulmoe. 2020.07.003.

28. Fu B, Xu X, Wei H. Why tocilizumab could be an effective treatment for severe COVID-19? J Transl Med 2020; 18: 164, DOI: 10.1186/s12967-020-02339-3.

29. Turnier JL, Brunner HI. Tocilizumab for treating juvenile idiopathic arthritis. Expert Opin Biol Ther, 16: 4, 559-566, DOI: 10.1517/14712598.2016.1150997.

30. Vercruysse F, Barnetche T, Lazaro E, et al. Adult-onset Still's disease biological treatment strategy may depend on the phenotypic dichotomy. Arthritis Res Ther 2019; 21: DOI: 10.1186/ s13075-019-1838-6.

31. Siegler EL, Kenderian SS. Neurotoxicity and cytokine release syndrome after chimeric antigen receptor T-cell therapy: in- 
sights into mechanisms and novel therapies. Front Immuno 2020; 11: DOI: 10.3389/fimmu.2020.01973.

32. Maude SL, Barrett D, Teachey DT, Grupp SA. Managing cytokine release syndrome associated with novel T cell-engaging therapies. Cancer J 2014; 20: 119-122: DOI: 10.1097/PPO. 0000000000000035.

33. Lee DW, Gardner R, Porter DL, et al. Current concepts in the diagnosis and management of cytokine release syndrome. Blood 2014; 124: 188-195, DOI: 10.1182/blood-2014-05-552729 [published correction appears in Blood 2015; 126: 1048, dosage error in article text; published correction appears in Blood 2016; 128: 1533]

34. Bonifant CL, Jackson HJ, Brentjens RJ, Curran KJ. Toxicity and management in CAR T-cell therapy. Mol Ther Oncolytics 2016; 3: 16011, DOI: 10.1038/mto.2016.11.

35. Le RQ, Li L, Yuan W, et al. FDA Approval summary: tocilizumab for treatment of chimeric antigen receptor T-cell-induced severe or life-threatening cytokine release syndrome. Oncologist 2018; 23: 943-947, DOI: 10.1634/theoncologist.2018-0028.

36. Klopfenstein T, Zayet S, Lohse A, et al. Impact of tocilizumab on mortality and/or invasive mechanical ventilation requirement in a cohort of 206 COVID-19 patients. Int J Infect Dis 2020; 99: 491-495, DOI: 10.1016/j.ijid.2020.08.024.

37. Somers EC, Eschenauer GA, Troost JP, et al. Tocilizumab for treatment of mechanically ventilated patients with COVID-19. Clin Infect Dis 2020; 73: e445-e454, DOI: 10.1093/cid/ciaa954.

38. Albertini L, Soletchnik M, Razurel A, et al. Observational study on off-label use of tocilizumab in patients with severe COVID-19. Eur J Hosp Pharm 2021; 28: 22-27, DOI: 10.1136/ ejhpharm-2020-002414.

39. Yuan X, Mu JS, Mo GX, et al. [Respiratory support for severe 2019-nCoV pneumonia suffering from acute respiratory failure: time and strategy]. Zhonghua Jie He He Hu Xi Za Zhi 2020; 43: 177-180, DOI: 10.3760/cma.j.issn.1001-0939.2020.03.006 [Article in Chinese].

40. Kataoka H, Kodama F, Tomita T, et al. Immediate amelioration of severe respiratory distress in Sjögren's syndrome with COVID-19 Treated with a single dose of off-label tocilizumab. Intern Med 2021; 60: 639-643, DOI: 10.2169/internalmedicine. 6010-20.

41. Kewan T, Covut F, Al-Jaghbeer MJ, et al. Tocilizumab for treatment of patients with severe COVID-19: a retrospective cohort study. EClinicalMedicine 2020; 24: 100418, DOI: 10.1016/ j.eclinm.2020.100418.

42. Ruscitti P, Berardicurti O, Iagnocco A, Giacomelli R. Cytokine storm syndrome in severe COVID-19. Autoimmun Rev 2020; 19: 102562, DOI: 10.1016/j.autrev.2020.102562.

43. Kaye AG, Siegel R. The efficacy of IL-6 inhibitor tocilizumab in reducing severe COVID-19 mortality: a systematic review. PeerJ 2020; 8: e10322, DOI: 10.7717/peerj.10322.

44. Boregowda U, Perisetti A, Nanjappa A, et al. Addition of tocilizumab to the standard of care reduces mortality in severe COVID-19: a systematic review and meta-analysis. Front Med (Lausanne) 2020; 7: 586221, DOI: 10.3389/fmed.2020.586221.

45. Tleyjeh IM, Kashour Z, Damlaj M, et al. Efficacy and safety of tocilizumab in COVID-19 patients: a living systematic review and meta-analysis. Clin Microbiol Infect 2021; 27: 215-227, DOI: 10.1016/j.cmi.2020.10.036.
46. Biran N, Ip A, Ahn J, et al. Tocilizumab among patients with COVID-19 in the intensive care unit: a multicentre observational study. Lancet Rheumatol 2020; 2: e603-e612, DOI: 10.1016/S2665-9913(20)30277-0.

47. Carvalho V, Turon R, Goncalves B, et al. Effects of tocilizumab in critically ill patients with COVID-19: a quasi-experimental study. medRxiv 2021. DOI: 10.1101/2020.07.13.20149328 [Preprint].

48. Guaraldi G, Meschiari M, Cozzi-Lepri A, et al. Tocilizumab in patients with severe COVID-19: a retrospective cohort study. Lancet Rheumatol 2020; 2: e474-e484, DOI: 10.1016/S26659913(20)30173-9.

49. Rosas IO, Bräu N, Waters M, et al. Tocilizumab in hospitalized patients with severe Covid-19 pneumonia. N Engl J Med 2021; 384: 1503-1516, DOI: 10.1056/NEJMoa2028700.

50. Stone JH, Frigault MJ, Serling-Boyd NJ, et al. Tocilizumab trial investigators. Efficacy of tocilizumab in patients hospitalized with Covid-19. N Engl J Med 2020; 383: 2333-2344, DOI: 10.1056/NEJMoa2028836.

51. RECOVERY Collaborative Group. Tocilizumab in patients admitted to hospital with COVID-19 (RECOVERY): a randomised, controlled, open-label, platform trial. Lancet 2021; 397: 16371645, DOI: 10.1016/S0140-6736(21)00676-0.

52. Salama C, Han J, Yau L, et al. Tocilizumab in patients hospitalized with Covid-19 pneumonia. N Engl J Med 2021; 384: 20-30, DOI: 10.1056/NEJMoa2030340.

53. Menzella F, Fontana M, Salvarani C, et al. Efficacy of tocilizumab in patients with COVID-19 ARDS undergoing noninvasive ventilation. Crit Care 2020; 24: 589, DOI: 10.1186/s13054-02003306-6.

54. Rossotti R, Travi G, Ughi N, et al. safety and efficacy of anti-IL6-receptor tocilizumab use in severe and critical patients affected by coronavirus disease 2019: a comparative analysis. J Infect 2020; 81: e11-e17, DOI: 10.1016/j.jinf.2020.07.008.

55. Stasi C, Fallani S, Voller F, Silvestri C. Treatment for COVID-19: an overview. Eur J Pharmacol 2020; 889: 173644, DOI: 10.1016/j.ejphar.2020.173644

56. Hariyanto TI, Kurniawan A. Tocilizumab administration is associated with the reduction in biomarkers of coronavirus disease 2019 infection. J Med Virol 2020; 93: 1832-1836, DOI: 10.1002/jmv.26698.

57. Moes DJ, van Westerloo DJ, Arend SM, et al. Fixed dosing of tocilizumab in ICU admitted COVID-19 patients is a superior choice compared to bodyweight based dosing; an observational population pharmacokinetic and pharmacodynamic study. medRxiv 2021; 05.10.21256933, DOI: 10.1101/2021.05.10.21256933 [Preprint].

58. Faroogi F, Dhawan N, Morgan R, et al. Treatment of severe COVID-19 with tocilizumab mitigates cytokine storm and averts mechanical ventilation during acute respiratory distress: a case report and literature review. Trop Med Infect Dis 2020; 5: 112, DOI: 10.3390/tropicalmed5030112.

59. Tsang HF, Chan LWC, Cho WCS, at al. An update on COVID-19 pandemic: the epidemiology, pathogenesis, prevention and treatment strategies. Expert Rev Anti Infect Ther 2020; 877888: 1-12, DOI: 10.1080/14787210.2021.1863146.

60. Matrajt L, Eaton J. Optimizing vaccine allocation for COVID-19 vaccines: critical role of single-dose vaccination. medRxiv 2021; 12.31.20249099, DOI: 10.1101/2020.12.31.20249099 [Preprint]. 